\title{
A Study to Evaluate the Combined Use of Alvarado Score and Imaging for Diagnosis of Acute Appendicitis
}

\author{
Arunima Mukhopadhyay ${ }^{1}$, Resham Chandra Majhi², Ujjwal Bhattachariya ${ }^{3}$, Ramprasad Dey ${ }^{4}$ \\ ${ }^{1}$ Department of Surgery, Calcutta National Medical College, Kolkata, West Bengal, India. ${ }^{2}$ Department of \\ Surgical Oncology, B L Kapur Memorial Hospital, New Delhi, India. ${ }^{3}$ Department of Surgery, Calcutta \\ National Medical College, Kolkata, West Bengal, India. ${ }^{4}$ Department of Obstetrics and Gynaecology, \\ Chittaranjan Seva Sadan, College of Obstetrics and Gynaecology and Child Health, West Bengal, India.
}

\section{ABSTRACT}

\section{BACKGROUND}

Acute appendicitis is one of the most common abdominal emergencies encountered in surgical practice. The diagnosis of acute appendicitis is an enigmatic challenge. Several studies have reported a variable diagnostic accuracy with a negative appendicectomy rate varying from $3 \%$ up to $20 \%$ using combined diagnostic modalities or using Alvarado score alone. The present study was carried out to evaluate the diagnostic efficacy of combined use of Alvarado score and imaging modalities (USG and / or CECT abdomen) for preoperative diagnosis of acute appendicitis.

\section{METHODS}

The present study was a prospective observational study carried out in a tertiary hospital of a metropolitan city. The study period extended over two years, from January 2016 till December 2018. The study included 118 adults who presented with clinical features of acute appendicitis. Alvarado scoring system based mainly on clinical features was applied and graded. Compression USG was performed on all patients. CECT of abdomen was done in 30 patients having inconclusive results on USG. Appendicectomy was performed on all the patients after the Alvarado scoring and imaging. The histopathological findings of the surgical specimens were noted to confirm the pathological diagnosis. The sensitivity, specificity, PPV, NPV and accuracy of the diagnostic methods were calculated.

\section{RESULTS}

Out of 118 appendicectomies, 104 were found to be positive on histopathology, with an overall $11.86 \%$ negative appendicectomy rate. Combined use of imaging with a high Alvarado score (7-10) had a sensitivity of 95.74\%, specificity of $100 \%$, accuracy of $95.8 \%$. Combined use of imaging with a low Alvarado score (3-6) had a sensitivity of $89.47 \%$, specificity of $53.8 \%$, accuracy of $82.85 \%$. Alvarado score alone had a sensitivity of $45.19 \%$, specificity of $92.85 \%$ and accuracy of $50.8 \%$. USG alone showed a sensitivity of $71.15 \%$, specificity of $71.42 \%$ and accuracy of $71.18 \%$. CECT alone had a sensitivity of $88 \%$, specificity of $60 \%$ and accuracy of $83.3 \%$.

\section{CONCLUSIONS}

Imaging modalities have a valuable role in terms of diagnostic accuracy particularly in cases having low Alvarado score. CECT though expensive is preferable to USG. However, the combined methodology of Alvarado scoring, and imaging is a rational approach for accurate diagnosis preventing surgical complications and minimizing negative appendicectomy rate.

\section{KEY WORDS}

Alvarado Scoring, Imaging in Acute Abdomen, Negative Appendicectomy Rate
Corresponding Author: Dr. Arunima Mukhopadhyay, \#836 Block-P, New Alipore, Kolkata-700053, West Bengal, India.

E-mail:ram_arunima@yahoo.co.in drrpdey@gmail.com DOI: 10.14260/jemds/2020/183

Financial or Other Competing Interests: None.

How to Cite This Article: Mukhopadhyay A, Majhi RC, Bhattachariya $U$, et al. A study to evaluate the combined use of alvarado score and imaging for diagnosis of acute appendicitis. J. Evolution Med. Dent. Sci. 2020;9(11):851-855, DOI: $10.14260 / \mathrm{jemds} / 2020 / 183$

Submission 06-01-2020,

Peer Review 20-02-2020,

Acceptance 26-02-2020,

Published 16-03-2020.
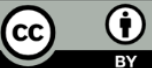


\section{BACKGROUND}

Acute appendicitis is one of the most common abdominal emergencies encountered by the general surgeon.[1-5] Although acute appendicitis as a known surgical entity has been successfully managed for more than a century, its diagnosis is still an enigmatic challenge and may baffle the best clinician. ${ }^{[1,2]}$ If left untreated, acute appendicitis can lead to perforation and peritonitis with high morbidity and mortality.[1-5] Worldwide perforated appendicitis is one of the leading general surgical cause of death. ${ }^{[5]}$ Appendicitis needs to be considered in the differential diagnosis of almost every patient with acute abdominal pain.[1-5] Surgeons face a persistent challenge to make the diagnosis correctly and make it early enough to prevent the disease from advancing with attendant morbidity. Several reported studies have used various diagnostic tools to establish diagnostic accuracy and reduce negative appendicectomy rate. Few studies using Alvarado scoring and imaging have reported that imaging is particularly helpful in presence of low score.[6-8] Some of the other studies have found imaging to be a valuable diagnostic tool irrespective of Alvarado score. ${ }^{[9-14]}$ Few other similar studies have found Alvarado scoring to be comparatively more reliable with imaging often giving inconsistent results.[15-17] Some other studies have used only Alvarado score for diagnosis and have reported a variable negative appendicectomy rate up to $20 \%$.[18-23]

All the above studies have reported a negative appendicectomy rate varying from $3 \%$ up to $20 \%$ irrespective of the diagnostic tool. Despite the vast advances of diagnostic methods in gastrointestinal surgery, no single diagnostic tool has been able to reduce the negative appendicectomy rate to zero. Negative appendicectomies are associated with unnecessary expenditure to patients and hospitals, congestion of theatres, avoidable exposure to anaesthesia, and preventable postoperative morbidity. Thus, globally surgeons are trying to develop a rational approach to increase diagnostic accuracy, avoid complications and minimize negative appendicectomy rate. The present study was based on the combined use of Alvarado score and imaging modalities (ultrasonography and/or CECT abdomen) for accurate preoperative diagnosis.

The aim of this study was to evaluate the diagnostic efficacy of combined use of Alvarado score and imaging modalities for preoperative diagnosis of acute appendicitis correlating it with the gold standard of histopathology.

\section{METHODS}

This study was a prospective observational study carried out in a tertiary hospital of a metropolitan city with a catchment area extending to the surrounding districts. The study population consisted of patients attending the surgical OPD/ Emergency consecutively and subsequently admitted with clinical features of acute appendicitis within the study period. Approval was taken from the institutional ethics committee regarding use of routine preoperative diagnostic abdominal sonography and selective CECT abdomen followed by elective appendicectomy in all the symptomatic cases based on
Alvarado score. The study period extended over two years from January 2016 till December 2018. The patients having clinical features of acute appendicitis were explained in their own language about the procedures involved in the study. 118 adult patients were recruited for the study following informed written consent in a prescribed proforma (in both English/local languages) for admission, clinical examination, preoperative imaging and surgery. Paediatric cases, patients having generalized peritonitis, palpable abdominal lump and pre-existing intra-abdominal diseases were excluded from the study.

Alvarado scoring was applied on all patients after admission based on symptoms, signs and peripheral blood smear study as follows: Presence of migrating right iliac fossa (RIF) pain, anorexia, nausea, rebound tenderness, elevated temperature and shift to left in peripheral smear were assigned a score of 1 each while presence of RIF tenderness and leucocytosis received a score of 2 each. The final score was given out of 10 . Traditionally a score of $9-10$ is very probable of appendicitis, score of 7-8 is probably appendicitis and a score of 5-6 is compatible with appendicitis. ${ }^{[1-5]}$

All patients had abdominal sonography after Alvarado scoring. Sonographic criteria used for diagnosis of acute appendicitis were as follows.[2-8]

1. Visualisation of non-compressible appendix of $6 \mathrm{~mm}$ or greater in anteroposterior diameter.

2. Wall thickness of appendiceal wall $>3 \mathrm{~mm}$.

3. Presence of faecolith in appendiceal lumen.

4. Peri appendiceal fluid or mass/ increased echogenicity of surrounding fat $>4 \mathrm{~mm}$.

CECT of abdomen was advised for those patients having inconclusive results on USG. The CECT criteria for diagnosis of acute appendicitis were as follows.[2-6]

1. Visualisation of dilated appendix $>7 \mathrm{~mm}$ in diameter.

2. Circumferential wall thickening and enhancement.

3. Thick walled appendix that did not fill with enteric contrast.

4. Peri appendiceal fat stranding/ fluid or abscess.

Appendicectomy was performed on all the patients after Alvarado scoring and imaging. During appendicectomy morphological findings consistent with appendicitis like presence of inflammation, perforation, faecolith, peri appendiceal fluid collection etc. were noted and all specimens were sent for histopathology. The histopathological results were regarded as confirmation of final diagnosis. The histopathological findings used for confirmation were as follows. ${ }^{[1-5]}$

1. Presence of mucosal and submucosal inflammation.

2. Extension of neutrophilic infiltration into muscularis propria.

3. Evidence of acute suppuration/necrosis of appendiceal wall/perforation/ gangrene.

\section{Statistical Analysis}

Data analysis was performed using statistical calculators like sensitivity, specificity, positive and negative predictive values and accuracy of Alvarado score, ultrasonography and CECT as individual or combined diagnostic modalities correlating with gold standard of histopathology using SPSS software and XLSTAT. 


\section{RESULTS}

For convenience of calculation, the patients having Alvarado score of 7-10 were considered to have positive Alvarado score and placed in Group A. Those having Alvarado score of 3-6 were considered having negative Alvarado score and placed in Group -B. There were 48 (28 males, 20 females) patients in Group A. 40 (24 males, 16 females) of them had a positive USG report and after appendicectomy had a positive histopathology. Another 5 ( 3 males 2 females) had negative USG but positive CECT and after surgery had positive histology. Rest of the 3 ( 1 male, 2 females) patients could not afford CECT. But as they had a high score, they were operated upon in spite of a negative USG. Histology was found to be positive in 2 ( 1 male, 1 female) and negative in 1 female.

There were 70 (30 males, 40 females) patients in Group B.USG was positive in 38 (16 males, 22 females) patients. After appendicectomy, histology was found to be positive in 34 (15 males, 19 females) and negative in 4 (1 male, 3 females). USG was negative in rest of the 32 (14 males, 18 females) patients and CECT was advised. 25 (13 males, 12 females) patients had CECT. CECT was positive in 19 of them. Histology was positive in 17(11 males, 6 females) and negative in 2 ( 1 male, 1 female). CECT was negative in the other 6 patients. As symptoms persisted, appendicectomy was done and histology was positive in 3 ( 1 male, 2 females) and negative in 3 ( 3 females). The remaining 7 patients of Group B could not afford CECT but had surgery due to persisting symptoms. Histology was positive in 3 (1 male, 2 females) and negative in 4 ( 4 females).

\begin{tabular}{|c|c|c|c|c|c|}
\hline $\begin{array}{c}\text { Alvarado } \\
\text { Score }\end{array}$ & $\begin{array}{c}\text { HPE } \\
\text { Positive } \\
\text { Male }\end{array}$ & $\begin{array}{l}\text { (104) } \\
\text { Female }\end{array}$ & $\begin{array}{c}\text { HPE } \\
\text { Negative } \\
\text { Male }\end{array}$ & $\begin{array}{l}\text { (14) } \\
\text { Female }\end{array}$ & $\begin{array}{c}\text { No. of } \\
\text { Patients }\end{array}$ \\
\hline Group-A (7-10) & 28 & 19 & 00 & 01 & 48 \\
\hline Group-B (3-6) & 28 & 29 & 02 & 11 & 70 \\
\hline \multicolumn{6}{|c|}{$\begin{array}{c}\text { Table I. Correlation of Alvarado Score with } \\
\text { Histopathology after Appendicectomy }\end{array}$} \\
\hline \multicolumn{6}{|c|}{$\begin{array}{l}\text { True Positive }=47 . \text { True Negative }=13 \text {, False Positive }=1 \text {, False Negative }=57 . \\
\text { Sensitivity }=45.19 \% . \text { Specificity }=92.85 \% . P P V=97.91 \% . \text { NPV }=18.57 \% . \\
\text { ACCURACY }=50.8 \% .\end{array}$} \\
\hline
\end{tabular}

\begin{tabular}{|c|c|c|c|c|c|}
\hline $\begin{array}{c}\text { USG } \\
\text { Findings }\end{array}$ & $\begin{array}{c}\text { HPE } \\
\text { Positive } \\
\text { Male }\end{array}$ & $\begin{array}{l}\text { (104) } \\
\text { Female }\end{array}$ & $\begin{array}{l}\text { HPE } \\
\text { Negative } \\
\text { Male }\end{array}$ & $\begin{array}{c}\text { (14) } \\
\text { Female }\end{array}$ & $\begin{array}{c}\text { No. of } \\
\text { Patients }\end{array}$ \\
\hline Positive & 39 & & 01 & & 78 \\
\hline Negative & 17 & 13 & 01 & 09 & 40 \\
\hline \multicolumn{6}{|c|}{ Table II. Correlation of USG with Histopathology after Appendicectomy } \\
\hline \multicolumn{6}{|c|}{$\begin{array}{l}\text { True Positive }=74 . \text { True Negative }=10 . \text { False Positive }=4 . \text { False Negative }=30 . \\
\text { Sensitivity }=71.15 \% . \text { Specificity }=71.42 \% . \text { PPV }=94.87 \% . \mathrm{NPV}=25 \% . \text { ACCURACY }= \\
71.18 \% .\end{array}$} \\
\hline
\end{tabular}

\begin{tabular}{|c|c|c|c|c|c|}
\hline $\begin{array}{c}\text { CECT } \\
\text { Findings }\end{array}$ & $\begin{array}{l}\text { HPE } \\
\text { Positive } \\
\text { Male }\end{array}$ & $\begin{array}{c}\text { (25) } \\
\text { Female }\end{array}$ & $\begin{array}{l}\text { HPE } \\
\text { Negative } \\
\text { Male }\end{array}$ & $\begin{array}{c}\text { (05) } \\
\text { Female }\end{array}$ & $\begin{array}{l}\text { No. of } \\
\text { Patients }\end{array}$ \\
\hline Positive & 14 & 08 & 01 & 01 & 24 \\
\hline Negative & 01 & 02 & 00 & 03 & 06 \\
\hline \multicolumn{6}{|c|}{$\begin{array}{l}\text { Table III. Correlation of CECT with } \\
\text { Histopathology after Appendicectomy }\end{array}$} \\
\hline $\begin{array}{l}\text { True Positiv } \\
\text { Sensitivity = } \\
83.33 \% \text {. }\end{array}$ & $\begin{array}{l}\text { 22. True N } \\
\% \text {. Specific }\end{array}$ & $\begin{array}{l}\text { yative }=3 . \\
y=66 \% . P I\end{array}$ & $\begin{array}{l}\text { se Positive }= \\
=91.66 \% . \mathrm{N}\end{array}$ & $\begin{array}{l}\text { False Neg } \\
=50 \% . \mathrm{A}\end{array}$ & $\begin{array}{l}=3 . \\
\mathrm{ZACY}=\end{array}$ \\
\hline
\end{tabular}

Out of 118 patients having appendicectomy in our study, 104 [56 males, 48 females] had positive histology for appendicitis while 14 [2 males, 12 females] were histologically negative for appendicitis. The negative appendicectomy rate was $11.86 \%$. The results of our study are tabulated as described below. Table I shows the correlation of Alvarado score of all patients with the gold standard of histopathology obtained after appendicectomy. Table-II shows the results when the USG findings of all patients were correlated with the histopathology. Table - III shows the CECT findings of 30 of the studied patients correlated with histopathology. Tables-IV shows the results of combined use of Alvarado score (both high \& low) and imaging in correlation to histopathology. The statistical results have been calculated separately in the patients with high/low score. Table-V shows the comparative statistics when Alvarado score, USG, CECT were used as separate or combined diagnostic modalities.

\begin{tabular}{|c|c|c|c|c|c|c|}
\hline $\begin{array}{l}\text { Alvarado } \\
\text { Score }\end{array}$ & Imaging & $\begin{array}{l}\text { HPE } \\
\text { Positive } \\
\text { Male }\end{array}$ & $\begin{array}{l}\text { (104) } \\
\text { Female }\end{array}$ & $\begin{array}{l}\text { HPE } \\
\text { Negative } \\
\text { Male }\end{array}$ & $\begin{array}{l}\text { (14) } \\
\text { Female }\end{array}$ & $\begin{array}{c}\text { No. of } \\
\text { Patients }\end{array}$ \\
\hline \multirow{2}{*}{ High (7-10) } & Positive & 27 & & 00 & 00 & \\
\hline & & & & & & \\
\hline \multirow{2}{*}{ Low (3-6) } & & & & & & \\
\hline & & & & 00 & & \\
\hline \multicolumn{7}{|c|}{$\begin{array}{c}\text { Table IV. Correlation of Combined Use of Alvarado Score } \\
\text { and Imaging with Histopathology }\end{array}$} \\
\hline \multicolumn{7}{|c|}{$\begin{array}{l}\text { In High Alvarado Score: True Positive }=45 . \text { True Negative }=1 . \text { False Positive }=0 . \\
\text { False Negative }=2 . \text { Sensitivity }=95.74 \% . \text { Specificity }=100 \% . P P V=100 \% . N P V= \\
33.3 \% . \text { Accuracy }=95.83 \% . \\
\text { In Low Alvarado Score: } \text { True Positive }=51 . \text { True Negative }=7 . \text { False Positive }=6 . \\
\text { False Negative }=6 . \text { Sensitivity }=89.47 \% . \text { Specificity }=53.8 \% . P P V=89.5 \% . \text { NPV }= \\
53.84 \% . \text { Accuracy }=82.85 \% .\end{array}$} \\
\hline
\end{tabular}

\begin{tabular}{|cccccc|}
\hline $\begin{array}{c}\text { Diagnostic } \\
\text { Modality }\end{array}$ & Sensitivity & Specificity & PPV & NPV & Accuracy \\
$\begin{array}{c}\text { Alvarado } \\
\text { Score }\end{array}$ & $45.1 \%$ & $92.85 \%$ & $97.91 \%$ & $18.57 \%$ & $50.8 \%$ \\
USG & $71.15 \%$ & $71.42 \%$ & $94.87 \%$ & $25 \%$ & $71.2 \%$ \\
$\begin{array}{c}\text { CECT } \\
\text { High Alvarado } \\
\text { Score + } \\
\text { Imaging }\end{array}$ & $98 \%$ & $60 \%$ & $91.66 \%$ & $50 \%$ & $83.3 \%$ \\
$\begin{array}{c}\text { Low Alvarado } \\
\text { Score + } \\
\text { Imaging }\end{array}$ & $89.5 \%$ & $100 \%$ & $100 \%$ & $33.3 \%$ & $95.8 \%$ \\
\hline \multicolumn{4}{|c|}{ Table V. Comparative Statistical Values of Alvarado Score, } \\
USG, CECT as Diagnostic Modalities \\
\hline
\end{tabular}

\section{DISCUSSION}

Acute appendicitis is a great mimicker and is notorious in its ability to simulate other intra-abdominal pathologies.[1-5] Surgeons have traditionally preferred to operate when the diagnosis is probable rather than wait until it is certain.[1-5] Negative appendicectomies are associated with unnecessary expenditure and avoidable postoperative morbidity related to pain, wound healing and limitation of daily activities. ${ }^{[6-10]}$ Delayed diagnosis, on the other hand leads to complications like perforation and peritonitis. ${ }^{[1-5]}$ To avoid both unwanted situations, several studies have used combined diagnostic modalities for accurate preoperative diagnosis.

In this study, Alvarado score, Ultrasonography and CECT whole abdomen were used as combined diagnostic modalities. 104 out of 118 patients had accurate preoperative diagnosis with a negative appendicectomy rate of $11.86 \%$. Alvarado score is easy and simple to calculate and can be carried out any time of the day. ${ }^{[1-5]}$ The statistical correlation of the Alvarado score with histopathology in the present study showed results somewhat similar to those obtained in some of the earlier studies, $[8,10,15]$ while some other studies had reported more accuracy.[9,17],[18-23] In this study it was 
noticed that Alvarado score is more accurate and reliable in case of higher scores (7-10), where $97.9 \%$ of symptomatic cases were found to be positive on histopathology. It was less reliable in lower scores $(<7)$ where about $18.6 \%$ of symptomatic patients were found to have negative histopathology. This has been similarly reported by other authors. $[8,9,10,12,15,17]$ also.

Graded compression USG is an inexpensive, fast and noninvasive method without any exposure to ionizing radiation. ${ }^{[1-5]}$ However it is operator dependent modality with high inter-observer variability.[8,9,10,15,17] CECT abdomen on the other hand is considered to be more effective due to less operator dependency and having a capability of better disease delineation.[1-4],[6,9] In our study, the efficacy of USG and CECT as diagnostic tools showed CECT to be more sensitive, specific and accurate and the results are comparable with those of other similar studies. ${ }^{99,11,12,16]}$

Our study showed that the diagnostic accuracy in cases of acute appendicitis is increased by the combined use of imaging modalities with Alvarado score rather than depending on scoring alone. It is particularly relevant in cases of low Alvarado score $(<7)$, to establish or exclude diagnosis thus minimizing complications. Several other studies.[6,7,10,15,17] have shown somewhat similar results particularly when the Alvarado score was around 6/7. The results of our study showed that CECT whole abdomen was reasonably accurate (83.3\%), if used as an independent diagnostic tool. However, its cost is a limiting factor for some patients. Even in this study, 10 of the patients could not afford it. It was also seen in this present study that the combined use of scoring and imaging as diagnostic modalities had a satisfactory diagnostic accuracy ranging from $80 \%$ $95 \%$, which was greater than that of Alvarado scoring or USG alone and was comparable to that of use of CECT alone.

Our results are comparable to those of other Indian authors over last ten years. ${ }^{[6-8,10,12]}$ Several of the studies used as references show that the combined diagnostic modalities of Alvarado scoring and imaging increase the diagnostic accuracy of acute appendicitis reducing negative appendicectomy rate.[6-9],[10-14] Our study had a negative appendicectomy rate (NAR) of $11.86 \%$ and the overall NAR for females was higher compared to that of males. (18.33\% vs $3.45 \%)$. We found that imaging is particularly helpful in females having low Alvarado score to exclude other pelvic diseases (adnexal pathology, ileocaecal and genital tuberculosis etc) mimicking acute appendicitis. All the studies used as references have reported a NAR varying from $3 \%$ up to $20 \%$ with a higher NAR for females. $[6,10,23]$

\section{Limitations}

The patients were clinically examined and assigned an Alvarado score by different surgeons, and USG reporting done by different radiologists with chances of interobserver variation. Cost of CECT abdomen was a limiting factor because 10 of the enrolled patients needing CECT could not afford it out of whom 5 were operated upon in spite of a low Alvarado score and inconclusive USG and found to be histopathologically negative. A larger sample size would have been more helpful for statistical interpretation.

\section{CONCLUSIONS}

Imaging modalities have a valuable role in terms of diagnostic accuracy particularly in cases having low Alvarado score. CECT though expensive is preferable to USG. Alvarado score alone is a less reliable diagnostic tool in comparison to imaging modalities particularly in scores <7. However, the combined methodology of Alvarado score and imaging is a rational approach for accurate diagnosis preventing surgical complications and minimizing negative appendicectomy rate.

\section{REFERENCES}

[1] Jurgen M. The vermiform appendix. Bailey \& Love's Short Practice of Surgery. 27th edn. CRC Press 2018: p. 1299317.

[2] Madenci AL, Peranteau WH, Smink DS. Appendix \& small bowel diverticula. Maingot's Abdominal Operations. $13^{\text {th }}$ edn. McGraw-Hill Publication 2019: p. 1813-79.

[3] Bryan R. The Appendix. Sabiston Textbook of Surgery. The biological basis of modern surgical practice. $20^{\text {th }}$ edn. Elsevier Publication 2017: p. 1296-311.

[4] Dahdaleh FS, Heidt D, Turaga KK. The Appendix. Schwartz's Priniples of Surgery. 11th edn. McGraw-Hill Publcation 2019: p. 1331-44.

[5] Maa J, Kirkwood KS. The appendix. In: Townsend CM Jr, Beauchamp RD, Evers BM, et al. eds. Sabiston textbook of surgery: the biological basis of modern surgical practice. 19th edn. Philadelphia, PA: Elsevier Saunders 2012: p. 1279-93.

[6] Ramashankar MM, Pandey R, Saini VC, et al. Safeguarding surgeons: Utility of USG\& CT in reducing diagnostic errors in acute appendicitis. J Clin \& Diag Res 2019;13 (9):PC07-PC09.

[7] Mishra A, Kumar SS, Sinha A. Diagnosis of acute appendicitis using modified Alvarado score and abdominal ultrasound. J Clin \& Diag Res 2018;12 (4):PC08-PC11.

[8] Kansakar N, Agarwal PN, Singh R, et al. Evaluation of combined use of modified Alvarado score and ultrasound in predicting acute appendicitis: a prospective study. Int Surg Journal 2018;5 (11):3594-7.

[9] Al-Faouri AF, Ajarma KY, Al-Abbadi AM, et al. The Alvarado score versus computed tomography in the diagnosis of acute appendicitis: a prospective study. Med J Armed Forces India 2016;72 (4):332-7.

[10] Nautiyal H, Ahmad S, Keshwani NK, et al. Combined use of modified Alvarado score and USG in decreasing negative appendicectomy rate. Indian Journal of Surgery 2010;72 (1):42-8.

[11] Toorenvliet BR, Wiersma F, Bakker RFR, et al. Routine ultrasound and limited computed tomography for the diagnosis of acute appendicitis. World Journal of Surgery 2010;34 (10):2278-85.

[12] Vaghela K. Shah B. Diagnosis of acute appendicitis using clinical Alvarado scoring system and computed tomography criteria in patients attending Gujarat Adani Institute of Medical Sciences. A retrospective study. Pol J Radiol 2017;82:726-30. 
[13] Chan I, Bicknell SG, Graham M. Utility and diagnostic accuracy of sonography in detecting appendicitis in a community hospital. Am J Roengenol 2005;184 (6):1809-12.

[14] Shirazi AS, Sametzadeh M, Kamankesh R, et al. Accuracy of sonography in diagnosis of acute appendicitis running. Pakistan Journal of Biological Sciences 2010;13 (4):1903.

[15] Nasiri S, Mohabbi F, Sodagari N, et al. Diagnostic values of ulirasound and the modified Alvarado scoring system in acute appendicitis. Int J Emerg Med 2012;5:26.

[16] Flum DR, McChire TD, Morris A, et al. Misdiagnosis of appendicitis and the use of diagnostic imaging. J Am Coll Surg 2005;201(6):933-9.

[17] Sathyajeet KS, Kunal KS, Chitrangada S, et al. Comparative study of diagnostic accuracy of modified Alvarado score \& USG in acute appendicitis. IOSR Journal of Dental \& Medical Sciences 2014;13 (1):36-40.

[18] Salam SS, Hajong R, Chinglesana L, et al. Diagnosis of acute appendicitis by Alvarado scoring. Indian Medical Journal 2007;101(9):314-8.
[19] Kalan M, Talbot D, Cunliffe WJ, et al. Evaluation to the modified Alvarado score in the diagnosis of acute appendicitis- a prospective study. Ann R Coll Surg Engl 1994;76 (6):418-9.

[20] Dey S, Mohanta PK, Baruah AK, et al. Alvarado scoring in acute appendicitis, a clinicopathological correlation. Indian J Surg 2010;72 (4):290-3.

[21] Memon AZ, Irfan S, Fatima K, et al. Acute appendicitis: Diagnostic accuracy of Alvarado scoring system. Asian J Surg 2013;36 (4):144-9.

[22] Kirkil C, Karabulut K, Aygen E, et al. Appendicitis scores may be useful in reducing the costs of treatment for right lower quadrant pain. Turkish J Trauma Emerg Surg 2013;19 (1):13-9.

[23] Tekeli MT, Ilhan E, Ureyen 0, et al. How much reliable is Alvarado scoring system in reducing negative appendicectomy? Indian J Surg 2017;79 (2):106-10. 